\title{
Educação em direitos humanos: implicações para as religiões no contexto brasileiro
}

\author{
Human rights education: \\ implications for religions in the brazilian context
}

\begin{abstract}
Adriano Sousa Lima*
Resumo

A educação em direitos humanos é essencial para o desenvolvimento pleno da personalidade, para a consolidação da cidadania e para promover a cultura da solidariedade, constituindo um dos principais desafios contemporâneos. Aqui reside o papel fundamental das instituições públicas e privadas, na medida em que as mesmas são desafiadas a criar, promover e fortalecer a cultura dos direitos humanos nos seus espaços de convivência. $\mathrm{O}$ texto adota como metodologia a análise de bibliografia especializada. Nessa direção, investiga-se os principais instrumentos normativos e diretivos da sociedade brasileira, tais como a Constituição Federal, a Lei de Diretrizes e Bases da Educação, a Declaração Universal dos Direitos Humanos e outros documentos que tratam da educação e dos direitos humanos, com o objetivo de extrair algumas implicações para a práxis religiosa. 0 percurso inicia analisando o texto constitucional que estabelece a educação como direito de todos, bem como seus respectivos objetivos; na sequência, a partir da Declaração Universal de 1948, faz-se uma reflexão sobre a educação em direitos humanos e sua importância para a consolidação da cidadania; ao concluir, o autor apresenta as implicações da educação em direitos humanos no contexto religioso brasileiro: a educação em direitos humanos promove a liberdade e a igualdade; promove uma educação comprometida com o desenvolvimento humano e com a cultura da solidariedade; e promove a amizade entre as diferentes religiões.
\end{abstract}

Palavras-chave: Educação. Direitos Humanos. Religião. Tolerância. Cidadania.

\begin{abstract}
Human rights education is paramount for a plain development of personality, for the consolidation of citizenship and to promote a culture of solidarity. So, it constitutes one of the most significant challenges nowadays. Public and private institutions are then expected to play a role in creating, promoting and strengthening the culture of human rights. The methodology developed is based on the analysis of specialized bibliography. This way, aiming to draw some implications for religious praxis, the current text investigates the main normative and guideline instruments in Brazilian society, such as the Federal Constitution, the Law for guidelines and basis of Education, the Universal Declaration of Human Rights and other documents that deal with education and human rights. The analysis starts with the constitutional text that establishes education as a right for everyone, as well as its respective objectives; afterwards based on the 1948 Universal Declaration it reflects on education in human rights and its importance to the consolidation of citizenship; at the end, the author shows human rights education implications to Brazilian religious context: human rights education promotes liberty and equality; it promotes an education that is committed with human development and with a culture of solidarity; and it promotes friendship among different religions.
\end{abstract}

Keywords: Education. Human Rights. Religion. Tolerance. Citizenship.

Artigo submetido em 30 de janeiro de 2019 e aprovado em 14 de abril de 2020.

* Doutor em Teologia pela PUCPR. Professor na Faculdade Batista do Paraná e no UNINTER. País de origem: Brasil. E-mail: adriano.lima.66@hotmail.com 


\section{Introdução}

A educação em direitos humanos é certamente um dos principais desafios contemporâneos. É necessário colocá-la nos currículos escolares, no café da manhã das famílias, nas reuniões dos funcionários da empresa, na roda de conversa entre amigos, nos púlpitos das igrejas e outros espaços religiosos, bem como em todos os lugares da vida cotidiana, com o objetivo principal de proteger a dignidade humana. Diante do atual contexto da sociedade brasileira, quando aumenta cada vez mais o desejo pelo lucro e diminui a preocupação com o ser humano (vide o rompimento das barragens em Mariana e Brumadinho), a educação emancipadora é com toda certeza o caminho mais viável. A educação que tem como objetivo formar profissionais para o mercado de trabalho, deveria visar também o aperfeiçoamento da cidadania e o pleno desenvolvimento da personalidade. Dessa forma, constitui inadiável tarefa a construção de uma educação que tenha comprometimento irrestrito com a vida humana.

Aqui reside a questão dos direitos humanos que é hoje motivo de muitas controvérsias. Alguns falam em defesa dos "verdadeiros direitos humanos", enquanto outros dizem que "direitos humanos é para humanos direitos". Por essa razão, é necessário apresentar logo de início o ponto de partida da presente reflexão. Nesse texto, a dignidade humana é o fundamento básico e principal para refletir sobre uma educação em direitos humanos. Assim, o caminho metodológico percorrido para a análise dos direitos humanos tem como referência a Declaração Universal de 1948, a Constituição da República Federativa do Brasil e outros instrumentos nacionais e internacionais, que norteiam e dão parâmetros para $o$ tema. Os documentos supramencionados serão interpretados e colocados em diálogo através de teólogos, juristas, educadores e cientistas das religiões, com o objetivo de estabelecer uma relação interdisciplinar entre educação, religião e direitos humanos.

As duas primeiras partes do texto serão dedicadas para uma análise detalhada do direito constitucional à educação de qualidade e seus respectivos objetivos. É importante compreender que a educação de qualidade não é privilégio 
e nem benefícios concedidos a um povo, mas um direito fundamental, essencial inclusive para o fortalecimento da democracia. No terceiro momento, os objetivos constitucionais da educação serão colocados em diálogo com os anseios da Declaração Universal dos Direitos Humanos, mais especificamente o seu artigo XXVI, que trata diretamente da educação/instrução. Desse diálogo será extraído algumas implicações para as religiões, tais como: o direito à igualdade, à solidariedade, à amizade e à tolerância religiosa. A proposta é que as religiões devem assumir tais elementos como essenciais nos seus discursos, pois assim estarão contribuindo para a promoção de uma educação em direitos humanos e consequentemente para elevar o patamar da dignidade humana de cada pessoa e fortalecer o Estado Democrático de Direito.

\section{0 direito constitucional à educação}

Nesse primeiro momento a educação será apresentada como direito fundamental, garantido pela Constituição da República Federativa do Brasil. Compreender essa perspectiva da educação é essencial para dimensionar a importância da mesma como processo constitutivo na construção de uma democracia. Não existe democracia sólida, sem educação em direitos humanos.

O artigo $6^{\circ}$ da Constituição Federal apresenta os direitos sociais que devem ser garantidos a todos os cidadãos brasileiros: "são direitos sociais a educação, a saúde, a alimentação, o trabalho, a moradia, o transporte, o lazer, a segurança, a previdência social, a proteção à maternidade e a infância, a assistência aos desamparados, na forma desta Constituição" (BRASIL, 1988). No rol dos direitos sociais, a educação é o direito primogênito. A Constituição Federal foi apelidada de Constituição cidadã, em virtude de sua ampla abertura aos direitos e garantias fundamentais. Aliás, a Constituição Federal de 1988 foi a primeira na história constitucional brasileira, a prever um título específico para os chamados direitos e garantias fundamentais (Título II) (SARLET, 2013). Nesse contexto, encontram-se os direitos e deveres individuais e coletivos, os direitos políticos, as regras sobre nacionalidade, os direitos sociais básicos e de caráter geral e ainda um conjunto de direitos dos trabalhadores, previstos no capítulo sobre os direitos sociais. 
A ampla garantia constitucional no que se refere aos direitos fundamentais e o compromisso com a justiça social, que aliás vem já do preâmbulo, faz parte de um processo evolutivo. Embora houvesse precedentes nas Constituições anteriores, foi apenas a partir de 1988 que os direitos sociais foram efetivamente positivados como autênticos direitos fundamentais. Essa positivação dos direitos sociais e trabalhistas está amparada por um contexto favorável e sólido. Se o preâmbulo da Constituição aponta para um compromisso com a justiça social, o bem-estar e a igualdade, o artigo $1^{\mathrm{o}}$ e inciso III coloca a dignidade humana como princípio do Estado Democrático de Direito. Diga-se de imediato, que existe absoluta relação entre a consolidação dos direitos sociais e a promoção da dignidade humana. Em outras palavras: não é possível promover a dignidade humana deixando de lado os direitos sociais fundamentais. Dada sua relevância, é importante apresentar um conceito de direitos sociais. Com a palavra, o professor José Afonso da Silva:

Podemos dizer que os direitos sociais, como dimensão dos direitos fundamentais do homem, são prestações positivas proporcionadas pelo Estado direta ou indiretamente, enunciadas em normas constitucionais, que possibilitam melhores condições de vida aos mais fracos, direitos que tendem a realizar a igualização de situações desiguais. São, portanto, direitos que se ligam ao direito de igualdade. Valem como pressuposto do gozo dos direitos individuais na medida em que criam condições materiais mais propícias ao auferimento da igualdade real, o que, por sua vez, proporciona condição mais compatível com o exercício efetivo da liberdade. (SILVA, 2018, p. 288).

Nas palavras do professor José Afonso da Silva, os direitos sociais estão estreitamente relacionados ao direito de igualdade. Tal perspectiva é fundamental nesse contexto, especificamente no que se refere à educação, pois diante das profundas desigualdades vivenciadas na sociedade brasileira, é desaconselhável falar em meritocracia. Nesse sentido, a efetivação dos direitos sociais contribui decisivamente para suprimir situações desiguais, possibilitando igualdade de oportunidade para todas as pessoas. Como ensina o ministro do STF, Gilmar Mendes, "o direito à educação tem assumido importância predominantemente para a concretização dos valores tutelados pela Constituição e, principalmente, para a construção de patamar mínimo de dignidade para os cidadãos" (MENDES, 2018, p. 706). Trata-se de um direito que tem elevada importância no processo de 
promoção da cidadania. A educação como direito de todos, deverá ser sempre uma educação emancipadora, que respeita as liberdades individuais e a autonomia humana. Não é uma educação reprodutora de desigualdades. A Educação emancipadora é comprometida com a dignidade humana, fundamento do Estado democrático de direito, consagrado no artigo $1^{\circ}$, inciso III da Constituição Federal. Trata-se de uma educação comprometida com os direitos humanos.

Assim, destaca-se entre os direitos sociais, o direito à educação, que aparece no já mencionado artigo $6^{\circ}$ da Constituição e de maneira ainda mais incisiva no artigo 205 da Carta Maior: "A Educação, direito de todos e dever do Estado e da Família, será promovida e incentivada com a colaboração da sociedade, visando ao pleno desenvolvimento da pessoa, seu preparo para o exercício da cidadania e sua qualificação para o trabalho" (BRASIL, 1988). Na lição sempre primorosa do professor José Afonso da Silva, a expressão a educação é direito de todos, combinada com o artigo $6^{\circ}$, eleva a educação ao nível dos direitos fundamentais do homem. E mais: "aí se afirma que a educação é direito de todos, com o que esse direito é informado pelo princípio da universalidade" (SILVA, 2018, p. 316). A educação é, portanto, compreendida como direito de todos, devendo ser promovida pelo Estado e pela família (arts 205 e 227). Nesse sentido, o que significa efetivamente a expressão educação direito de todos? Recorre-se mais uma vez à valiosa contribuição do professor aposentado de Direito Constitucional da USP, José Afonso da Silva:

A educação, direito de todos e dever do Estado e da família, significa, em primeiro lugar, que o Estado tem que aparelhar-se para fornecer, a todos, os serviços educacionais, isto é, oferecer ensino, de acordo com os princípios estatuídos na Constituição (art 206); que ele tem que ampliar cada vez mais as possibilidades de que todos venham a exercer igualmente esse direito; e, em segundo lugar, que todas as normas da Constituição, sobre educação e ensino, hão que ser interpretadas em função daquela declaração e no sentido de sua plena e efetiva realização. A Constituição mesmo já considerou que o acesso à educação básica é gratuito dos 4 aos 17 anos de idade, assegurada inclusive sua oferta gratuita para todos os que a ela não tiveram acesso na idade própria, é direito público subjetivo; equivale reconhecer que é direito plenamente eficaz e de aplicabilidade imediata, isto é, direito exigível judicialmente, se não for prestado espontaneamente. (SILVA, 2018, p. 317). 
A interpretação do texto constitucional do professor da USP destaca dois aspectos relevantes: em primeiro lugar, o Estado deve fornecer a todos os serviços educacionais. Essa oferta precisa ser de qualidade, sem exclusividade para alguns, deixando outros privados da educação e em conformidade com os princípios da Carta Magna. Em segundo lugar, é a especificidade da educação que deve ser assegurado à todas as pessoas, que norteia a hermenêutica das normas sobre educação e ensino, inclusive assegurando sua aplicação imediata, podendo ser requerida judicialmente, caso não seja prestada espontaneamente. Portanto, é inadmissível que muitos brasileiros não tenham acesso à educação de qualidade. A luta pela efetivação do direito à educação de qualidade, deve ser assumida por todos aqueles que têm compromisso com o Brasil e com a sua democracia. Nesse contexto, as religiões têm papel relevante, como será discutido posteriormente.

A educação, como se verifica, possui lugar importante numa sociedade democrática e constitui elemento fundamental na vida humana. Portanto, quando se fala em direito à educação, se está pois, a reconhecer o papel indispensável dos fatores sociais na formação do indivíduo. Ao comentar o artigo 205 da Constituição Federal, o professor Marcos Augusto Maliska lembra que a educação:

\footnotetext{
Não seria apenas uma formação, mas uma condição formadora necessária ao próprio desenvolvimento natural. Tal entendimento implica afirmar que o indivíduo não poderia adquirir suas estruturas mentais mais essenciais sem uma contribuição exterior; a exigir um certo meio social de formação, e que em todos os níveis (desde os mais elementares até os mais altos) o fator social ou educativo constitui uma condição do desenvolvimento. A educação como direito de todos, portanto, não se limita em assegurar a possibilidade da leitura, da escrita e do cálculo. A rigor, deve garantir a todos o pleno desenvolvimento de suas funções mentais e a aquisição dos conhecimentos, bem como dos valores morais que correspondam ao exercício dessas funções, até a adaptação à vida social atual. (MALISKA, 2013, p. 1964).
}

$\mathrm{Na}$ interpretação constitucional do professor Maliska, nota-se a dimensão integral da educação na formação humana. Não se trata de uma importância relativa ou secundária, mas fundamental, relevante, constitutiva e primorosa. Não é possível formação integral da personalidade humana sem uma educação de qualidade. Esta, contribui em todos os aspectos para uma formação crítica, 
autônoma, possibilitando alcançar a sua finalidade que é o pleno desenvolvimento da pessoa humana.

Apenas quando se verifica a educação sob esse ângulo, é possível ter consciência da sua importância e do seu valor na vida. Quando se fala em direito à educação, o que está em questão é um elemento essencial para a promoção da dignidade humana, para a consolidação do Estado de direito e para o fortalecimento da democracia. É importante compreender a educação desde a perspectiva constitucional, considerando seus objetivos e, sobretudo, a sua importância ímpar no desenvolvimento da cidadania. Como observa o professor Ricardo Castilho, o legislador "intuiu na Constituição a conclusão evidente de que ao lado do direito à educação, deve estar a obrigação de educar." (CASTILHO, 2016, p. 144). Nesse sentido, vale enfatizar desde já a contribuição da educação para o convívio social. Ao destacar os objetivos da educação, tais como o desenvolvimento da pessoa, o preparo para a cidadania e sua qualificação para o trabalho, o constituinte deixa claro o papel da educação na formação plena e integral do indivíduo.

O texto constitucional enfatiza o importante papel do Estado na promoção da educação para todos. Contudo, sabe-se que no Brasil, em razão da negligência por parte do Estado no que diz respeito ao oferecimento de uma rede educacional de qualidade, amplos e importantes setores da sociedade acabaram sendo prejudicados. Aqui reside especificamente um aspecto fundamental, que deve ser objeto de reflexão. O constituinte ao enfatizar que a educação é direito de todos e dever do Estado, deixou evidenciado que esta educação não pode ser de qualquer tipo ou especificidade, mas deve ser uma educação de qualidade.

O professor de direito constitucional e ministro do STF, Gilmar Mendes, ressalta o relevante papel desempenhado por uma educação de qualidade, especificamente na completa eficácia dos direitos políticos dos cidadãos. Para Mendes, uma educação de qualidade contribui principalmente no que se refere aos instrumentos de participação direta, como referendo e plebiscito. Nesse contexto, destaca o ministro: "as falhas na formação intelectual da população inibem sua 
participação no processo político e impedem o aprofundamento da democracia" (MENDES, 2018, 707). A qualidade da educação é aspecto relevante a ser considerado, pois não é possível pensar em formação que promova cidadania, dignidade humana e direitos humanos, a partir de uma educação moldada de qualquer forma e de baixa qualidade.

Na mesma toada, o professor André Ramos Tavares chama a atenção para o fato de que o direito à educação, justamente por ter fundamentos constitucionais não pode ser considerado qualquer direito. A Constituição garante o direito do acesso à educação. Contudo, lembra o professor da USP: "mas não um acesso a qualquer educação, e sim àquela que atende às preocupações constitucionais". O professor adverte ainda: "o dever estatal quanto ao direito fundamental à educação está longe de se esgotar no mero oferecimento de acesso. O poder público deve valorizar os profissionais da educação e ainda garantir um padrão mínimo de qualidade" (TAVARES, 2018, p. 770, 775). Verifica-se que o dever do Estado não se resume a oferecer o acesso à educação, mas zelar para que a mesma seja de qualidade para todos. É a união desses dois fatores (acesso à educação para todos e com qualidade) que contribuirá para que os fins da educação sejam alcançados. O professor Marcos Augusto Maliska também argumenta sobre a qualidade da educação, nos termos do artigo 206, inciso VII:

A garantia de qualidade impõe tanto em dever à escola de prestar o ensino com qualidade como um deve ao Estado de fiscalização. Ambas as situações geram um direito ao aluno de exigir uma educação escolar de qualidade, com professores qualificados, bibliotecas e laboratórios equipados, enfim, o direito de acesso aos meios necessários para que o processo educacional obtenha êxito. A definição do que seja uma educação escolar de qualidade tem como referência os critérios exigidos pelo Estado para a autorização de funcionamento da escola. Assim, aquelas que estejam abaixo desses critérios devem imediatamente tomar providências para adequarem-se às exigências dos órgãos fiscalizadores. (MALISKA, 2013, 1968).

Na concepção do professor Maliska, para que a educação seja de qualidade, Estado e escola precisam trabalhar juntos. O primeiro fiscalizando e propiciando condições para que a qualidade se estabeleça e a segunda prestando um ensino de qualidade. A escola deverá adequar-se aos critérios estabelecidos pelo Estado, os 
quais são fundamentais para a sua subsistência. Tais critérios encontram-se estabelecidos na Carta constitucional e na legislação complementar.

Em síntese, a educação de qualidade é um direito constitucional que deve ser garantido a todos os brasileiros. Trata-se de um direito que está absolutamente relacionado com outros direitos fundamentais, tais como a igualdade, a liberdade e a pluralidade. A educação é fundamental no processo de formação humana, na promoção da dignidade humana e na consolidação da cultura dos direitos

humanos. É a educação em direitos humanos que promove consciência crítica, responsabilidade social, cuidado com o meio ambiente e respeito às diversidades. Garantir esse direito fundamental é possibilitar a formação integral da personalidade humana e o fortalecimento da democracia.

\section{Os objetivos da educação}

Nesse segundo momento, serão analisados os objetivos da educação, considerando aqueles estabelecidos na Constituição Federal, no artigo 205: o pleno desenvolvimento da pessoa, o preparo para o exercício da cidadania e sua qualificação para o trabalho. Compreender a educação a partir de tais objetivos é fundamental para entender o relevante papel da mesma na sociedade de maneira geral e na vida das pessoas de maneira particular.

O artigo 205 da Constituição Federal aponta três objetivos específicos para a educação. Retomando o artigo supramencionado, tem-se: "A educação, direito de todos e dever do Estado e da Família, será promovida e incentivada com a colaboração da sociedade, visando ao pleno desenvolvimento da pessoa, seu preparo para o exercício da cidadania e sua qualificação para o trabalho" (BRASIL, 1988). Para que a educação seja transformadora, emancipadora e promova transformação na vida das pessoas e, consequentemente na sociedade, é absolutamente necessário alcançar tais objetivos. Nesse contexto, é fundamental analisar de forma individual cada objetivo da educação estabelecido na Carta constitucional. 


\subsection{O pleno desenvolvimento da pessoa}

O primeiro objetivo da educação como direito de todos é o pleno desenvolvimento da pessoa. Como mencionado, o objetivo encontra-se estabelecido no artigo 205 da Constituição Federal, sendo enfatizado também no artigo $2^{\circ}$ da Lei de Diretrizes e Bases da Educação (LDB). Considerando que a finalidade da educação diz respeito aos alinhamentos que orientam e organizam o funcionamento das instituições, com vistas ao educando que a escola se propõe a formar, o pleno desenvolvimento da pessoa é uma finalidade nobre. Afinal, toda educação deve ter como objetivo fundamental o desenvolvimento pleno do cidadão. Nas palavras do professor Moacir Carneiro, o pleno desenvolvimento do educando significa que:

A educação, como processo intencional, deve contribuir para que o organismo psicológico do aprendiz se desenvolva numa trajetória harmoniosa e progressiva. É o nível cognitivo em evolução, voltando-se para a assimilação de certos conhecimentos e de certas operações mentais. A primeira etapa da trajetória corresponde às aprendizagens desenvolvidas na fase inicial da evolução da criança. Aqui as aprendizagens estimulam a formação de hábitos sensório-motores. A segunda etapa corresponde à formação consciente de estruturas, ao entendimento e de relações fundamentais do mundo real. No nível cognitivo, as pessoas desenvolvem a aprendizagem na relação direta com o seu mundo e, também, no uso do vocabulário, à medida que as palavras são portadoras de sentido. São elas condição essencial de aprendizagem, uma vez que constituem a base dos conceitos com os quais nós pensamos. (CARNEIRO, 2015, p. 57).

O professor Moacir Carneiro enfatiza o caráter progressivo do processo educacional, apresentando as etapas da aprendizagem. Cada etapa tem sua importância e seu valor fundamental no processo evolutivo do desenvolvimento da pessoa, o que implica diretamente nas relações humanas. Portanto, esse objetivo da educação tem relevância social, importância pedagógica e prioridade didática à medida que sinalizam as políticas de educação para os vários sistemas bem como os balizamentos para assegurar o adequado detalhamento da proposta pedagógica.

O pleno desenvolvimento da pessoa é um direito fundamental, que implica sob o ponto de vista psicológico e sociológico, a distinção entre o indivíduo e a personalidade. Como argumenta Jean Piaget, “o indivíduo é o eu centrado sobre si 
mesmo e obstaculizando, por meio desse egocentrismo moral ou intelectual, as relações de reciprocidade inerentes a toda vida social evoluída”. E prossegue Piaget: "a pessoa, ao contrário, é o indivíduo que aceita espontaneamente uma disciplina, ou contribui para o estabelecimento da mesma, e dessa forma se submete voluntariamente a um sistema de normas recíprocas que subordinam a sua liberdade ao respeito de cada um.” (PIAGET, 1990, p. 60-61). Assim, o educador suíço define personalidade como "uma certa forma de consciência intelectual e de consciência moral, igualmente distanciada da anatomia peculiar ao egocentrismo e da heteronomia das pressões exteriores, porque ela realiza a sua autonomia adaptando-a à reciprocidades.” (PIAGET, 1990, p. 60-61). Nesse aspecto, o objetivo da educação, no que diz respeito ao pleno desenvolvimento da pessoa (personalidade humana) consiste em "formar indivíduos capazes de autonomia intelectual e moral e respeitadores dessa autonomia em outrem, em decorrência precisamente da regra de reciprocidade que a torna legítima para eles mesmos" (PIAGET, 1990, p. 61). Nesse contexto, toda educação (incluindo especialmente a religiosa e teológica) precisa buscar esse objetivo, no sentido de formar cidadãos plenamente desenvolvidos, que tenham liberdade de exercer autonomia, respeitando ao mesmo tempo a autonomia do outro. Esse é um caminho essencial na construção de uma sociedade civilizada e evoluída.

\subsection{O preparo para a cidadania}

É fundamental refletir ainda que minimamente sobre o conceito de cidadania. Este implica na condição básica de ser cidadão, ou seja, ser titular de direitos e de deveres. O cidadão não é apenas aquele que reconhece seus direitos, mas também o que reconhece suas responsabilidades cívicas. Nesses termos, exercer a cidadania compreende de um lado a luta intransigente na defesa dos direitos fundamentais; do outro lado, exige um compromisso sólido com os deveres individuais.

Historicamente, o conceito de cidadania nos leva à análise da polis grega, especialmente de Atenas, onde alcançou grande desenvolvimento. No primeiro 
momento, "a cidadania foi concebida como um conjunto de deveres e obrigações com relação à cidade, em que a esfera privada da vida do indivíduo é preterida em razão das obrigações políticas do cidadão" (AGRA, 2013, p. 120). O professor Walber Agra explica que com o passar dos tempos, o conceito evoluiu enfatizando não apenas a presença do cidadão no Estado, mas também fazendo com que ele se sinta parte de uma comunidade, onde tem direitos e responsabilidades.

Deve-se ressaltar que a cidadania é um dos fundamentos do Estado, nos termos do artigo $1^{0}$, inciso III da Carta constitucional. A concepção de cidadania adotada pela Constituição Federal coincide com a que foi introduzida pela Declaração Universal dos Direitos Humanos, relacionando-se diretamente ao movimento de incorporação dos direitos humanos, bem como ao movimento de máxima efetividade dos referidos direitos (TAVARES, 2018, p. 793). Existe, portanto uma estreita relação entre cidadania e direitos humanos (que será analisado mais detalhadamente à frente). E por consequência, tem-se a educação em direitos humanos, sem a qual não há que se falar em cidadania, no sentido mais profundo da palavra.

A educação tem também como objetivo contribuir para que a pessoa exerça de forma plena a cidadania. Formar pessoas conscientes e capazes de exercer de fato a cidadania é não apenas um objetivo, mas também um grande desafio para a educação. Afinal, somente cidadãos emancipados e informados podem contribuir para a construção de uma sociedade justa, ética, solidária e plural. Daí ser fundamental compreender o papel da educação na promoção de uma formação cidadã.

Ao analisar os objetivos constitucionais da educação nos termos do artigo 205 e a realidade da sociedade brasileira, é perceptível a distância que existe entre ambos. Lamentavelmente, parte considerável da população convive com a ausência de uma educação de qualidade, formação eficiente e assim ficam impossibilitados de exercer plenamente a cidadania. Nesses termos, as consequências recaem não apenas sobre cada pessoa individualmente, mas sobre toda a sociedade e, consequentemente enfraquece a democracia. Assim, vale enfatizar os diversos 
aspectos que envolvem o papel da educação em um Estado democrático. Portanto, pode-se dizer que a educação:

É um instrumento permanente de aperfeiçoamento humanístico da sociedade; (ii) promove a autonomia do indivíduo; (iii) promove a visão de mundo das pessoas, a forma como elas vão ver os acontecimentos na sua cidade, no seu país e no mundo. Ela deve ter a função de superadora das concepções de mundo marcadas pela intolerância, pelo preconceito, pela discriminação, pela análise não crítica dos acontecimentos; (iv) promove o sentimento de responsabilidade nas pessoas para com o mundo que vive, o sentimento de que o mundo que está a sua volta é um pouco resultado de suas próprias ações; (v) promove a consciência de que viver em uma República não implica apenas desfrutar direitos, mas também compreende responsabilidades cívicas e (vi) promove a consciência pelo valor dos direitos individuais. (MALISKA, 2013, p. 1965).

As diversas contribuições da educação para a vida humana ficam evidenciadas na lição precisa do professor Maliksa, na medida em que se verifica a dimensão que compreende uma formação cidadã. A educação como instrumento de formação humanística da sociedade, como já mencionado no texto, não é qualquer tipo de educação, mas uma educação comprometida, engajada e empenhada em promover a autonomia e a visão de mundo do indivíduo, que lhe possibilite a ver e participar do dia a dia do seu bairro, da sua cidade, do seu estado, do seu país e do mundo. A pessoa educada para a cidadania não fica alheia aos acontecimentos sociais, políticos e econômicos do seu país, pois sabe que tais acontecimentos podem afeta-lo positiva ou negativamente.

Alcançar esse objetivo estabelecido pela Constituição Federal para a educação, constitui elemento importante, pois na medida em que as pessoas são educadas para a cidadania, elas também são capazes de superar paradigmas marcados pela intolerância, pela falta de respeito ao diferente, pelo etnocentrismo e pelo preconceito. No contexto global, mas especificamente na sociedade brasileira, a capacidade de análise crítica e a superação de paradigmas do passado são cada vez mais necessários tanto para a convivência harmoniosa como para a preservação da sociedade tendo em vista as próximas gerações. 


\subsection{Qualificação para o trabalho}

O terceiro e último objetivo da educação, nos termos do artigo 205 da Constituição Federal é a qualificação para o trabalho. Como se sabe, a educação é elemento indispensável ao preparo profissional, especificamente na época contemporânea, onde o preparo intelectual razoável do trabalhador é exigido mesmo para realização de tarefas consideradas como trabalho não intelectual. Nesse contexto, a educação constitui um elemento cada vez mais essencial no sentido de preparar o ser humano para o mercado de trabalho. O professor Moacir Carneiro argumenta que:

O objetivo essencial da educação científica é a omnilateralidade do homem, visto que é no trabalho que ele se realiza. Expressão criadora e transformadora, o trabalho é o chão firme das chances de liberdade para o ser humano. Aprender, portanto, é conhecer e aprender a fazer [...] Este alicerce de todo o processo de realização individual e coletiva não pode permanecer divorciado da educação. A escola e os Sistemas de Ensino precisam entrar no mundo do trabalho e introduzi-lo como categoria de inspiração do currículo se, de fato, pretendem resgatar a sala de aula como um ambiente funcional para a sociedade tecnológica em metamorfose profunda. (CARNEIRO, 2015, p. 58).

Como é dever do Estado promover educação de qualidade para todos, cumpre a ele (Estado) também ofertar condições materiais mínimas para que todos possam conseguir qualificar-se para buscar um posto de trabalho. $\mathrm{Na}$ argumentação do professor Maliska, "a educação como instrumento permanente de aperfeiçoamento do trabalhador é algo inerente às sociedades como a nossa, marcadas pela dinamicidade e pela inovação, que a cada dia colocam novos desafios aos trabalhadores." (MALISKA, 2013, p. 1966). Assim é importante que o mundo da educação se insira no mundo do mercado de trabalho, para que juntos possam contribuir na realização humana.

A educação deve levar em consideração os desafios do mercado de trabalho tanto no momento presente como no futuro. Como adverte o historiador Yuval Noah Harari: "não temos ideia de como será o mercado de trabalho em 2050. Sabemos que o aprendizado de máquina e a robótica vão mudar quase todas as modalidades de trabalho - desde a produção de iogurte até o ensino de ioga". 
Diante de profundas transformações envolvendo o mercado de trabalho, a previsão do historiador israelita para as próximas décadas é que não estaremos diante da "substituição de milhões de trabalhadores humanos individuais por milhões de robôs e computadores individuais, mas, provavelmente, da substituição de humanos individuais por uma rede integrada." (HARARI, 2018, p. 40).

Diante do rápido e constante desenvolvimento tecnológico, provocando profundas transformações na sociedade, bem como o aumento do desemprego, é cada vez mais necessária uma educação alinhada que promove o desenvolvimento integral da personalidade, prepara o indivíduo para exercer a cidadania e o capacita para o mercado de trabalho. Ao mesmo tempo, o trabalho não deve ser instrumento de exploração e escravidão. Por essa razão, a educação deve ter sempre como ponto de partida, como alicerce fundamental, a prevalência dos direitos humanos.

\section{Educação em direitos humanos: implicações para as religiões}

O que é educação em direitos humanos? Quais os objetivos de uma educação voltada para os direitos humanos? Quais as implicações para as religiões? Nesse tópico, o objetivo é apresentar algumas respostas para os questionamentos supramencionados, sem nenhuma pretensão de esgotar o assunto, mas com o propósito de apresentar contribuições ao debate.

Inicialmente, é necessário entender o que é educação em direitos humanos. Nesse texto, assume-se o conceito do Programa Mundial para Educação em Direitos Humanos da ONU, em vigor desde 2005:

A educação em direitos humanos pode ser definida como um conjunto de atividades de educação, de capacitação e de difusão de informação, orientado para a criação de uma cultura universal de direitos humanos. Uma educação integral em direitos humanos não somente proporciona conhecimentos sobre os direitos humanos e os mecanismos para protegêlos, mas, além disso, transmite as aptidões necessárias para promover, defender e aplicar os direitos humanos na vida cotidiana das pessoas. A educação em direitos humanos promove as atitudes e o comportamento necessários para que os direitos humanos para todos os membros da sociedade sejam respeitados. (ONU, 2005). 
A partir do conceito apresentado pelo Programa Mundial para Educação em Direitos Humanos, é possível delimitar o ponto de partida da presente reflexão. Pensar em educação em direitos humanos é refletir sobre um conjunto de atividades, de capacitação e de informação, orientado para a criação de uma cultura universal dos direitos humanos. É cada vez mais urgente no mundo das ciências a reflexão desde a perspectiva global. Diante da consolidação da cultura da violência, do estupro, da intolerância, do preconceito e do ódio, urge a necessidade da criação e consolidação da cultura dos direitos humanos. Nesse aspecto, a educação em direitos humanos pode contribuir significativamente. Como explica o professor Mazzuoli, em suma:

A educação em direitos humanos deve ocorrer de forma a que os seus princípios éticos sejam assimilados por todos os cidadãos em sua plenitude, passando a orientar as ações das gerações presentes e futuras, em busca da reconstrução dos direitos humanos e da cidadania do país. Somente dessa maneira é que o exercício da cidadania e o respeito aso direitos humanos restarão completos e definitivamente assegurados, criando-se verdadeira cultura de direitos humanos entre nós. (MAZZUOLI, 2017, p. 475).

Deve-se enfatizar que a participação de todos os cidadãos, bem como as diversas instituições públicas e privadas são essenciais no processo de consolidação da cultura dos direitos humanos, a partir de uma educação com esse propósito. Os princípios fundamentais da educação em direitos humanos, tais como a igualdade e a não discriminação devem nortear as atividades das instituições, e não devem ficar apenas no aspecto teórico, mas prático formativo. Aqui reside o papel de uma das mais antigas instituições da sociedade, que é a religião. Esta teve e tem importância significativa na história da vida humana, "interferindo nos valores, nos comportamentos, nos sentimentos e inclusive, nas normas que advêm do pensamento e das regras religiosas." (ROSSI, JUNQUEIRA, 2015, p. 11). Daí a importância sempre atual da interface entre educação e direitos humanos, no sentido de extrair implicações fundamentais para o contexto religioso brasileiro. 


\subsection{A questão da igualdade}

O artigo 205 da Constituição Federal começa afirmando que todos têm direito à educação. A educação em direitos humanos enfatiza o aspecto da igualdade de condições para o acesso e permanência na escola. Nesse sentido, destaca-se a necessidade de promover a inclusão do maior número possível de pessoas para a educação, especialmente as camadas menos favorecidas e aquelas que historicamente tiveram seus direitos prejudicados, tais como negros, mulheres, etc. Nas universidades públicas, por exemplo, foram instituídos diversos programas com a finalidade de combater tanto a exclusão fundada em fatores de ordem socioeconômica, quanto nos de origem racial.

Vale ressaltar que o Supremo Tribunal Federal (STF) confirmou a constitucionalidade do Programa Universidade para Todos (PROUNI) e do programa de cotas para Universidade de Brasília. Como argumenta Mendes, "tratase de buscar o caminho mais adequado para promover ensino de qualidade que inclua todas as camadas da população e permita seu desenvolvimento completo" (MENDES, 2018, p. 709). Assim, a educação em direitos humanos busca enfatizar explicitamente o aspecto da igualdade, no sentido de garantir cada vez mais a todos, sem distinção, o direito à uma formação qualificada que permita o pleno desenvolvimento da personalidade.

A promoção da igualdade, na concepção de Boaventura de Souza Santos, insere-se nas lutas contra-hegemônicas pelos direitos humanos, cujo objetivo fundamental é "a mudança das estruturas sociais que são responsáveis pela produção sistemática de sofrimento humano injusto" (SANTOS, 2014, p. 140). A educação em direitos humanos é exatamente uma proposta de educação crítica que não se submete aos princípios de reprodução das desigualdades sociais. Num país onde a desigualdade é clara como a luz do sol, a educação em direitos humanos é urgente. 
No campo religioso (especialmente no Brasil), o direito de igualdade é enfatizado em duas frentes: por um lado, no relacionamento com o Estado, nenhuma religião pode ser detentora de privilégios em detrimento de outras. As religiões majoritárias não podem desfrutar de benefícios dos quais as religiões minoritárias são privadas. No Estado laico, as religiões são tratadas a partir do princípio de isonomia. Como exemplo, a Constituição Federal nos termos do artigo $5^{\circ}$, inciso VI garante igualmente a todos à liberdade de crença, o livre exercício dos cultos religiosos, a proteção aos locais de cultos e suas liturgias. É vedado tratamento aforado para uma religião específica no Brasil. Por outro lado, as religiões brasileiras e suas instituições devem promover políticas públicas que facilitem o acesso de pessoas que fazem parte dos grupos minoritários, no sentido de enfatizar o respeito às diversidades, promover a cultura dos direitos humanos $\mathrm{e}$ fortalecer o Estado Democrático de Direito. As escolas e universidades (confessionais ou públicas), os departamentos teológicos e de ciências das religiões, desempenham aqui papel fundamental. A promoção de políticas públicas que facilitem o acesso de pessoas de religiões minoritárias, como africanas e indígenas, por exemplo, é um importante processo para a promoção de uma educação religiosa em direitos humanos. Como afirma Jürgen Moltmann: "nas religiões proféticas do judaísmo, do cristianismo e do islamismo, a liberdade e a igualdade de todos os seres humanos são fundamentais a partir da fé na criação. Elas consistem na imagem de Deus de todos os seres humanos." (MOLTMANN, 2012, p. 258). Para tais tradições religiosas, todos os seres humanos são iguais, a despeito de sua idade, sexo, raça, religião e quaisquer outras diferenças.

Considerando que o objetivo da educação é preparar o indivíduo para a cidadania, as religiões podem contribuir efetivamente nesse processo, possibilitando a inclusão das diversidades e contribuindo no combate às perspectivas fundamentalistas e todo tipo de racismo, xenofobia, preconceito e dominação. Como precisamente afirmou o teólogo alemão Jürgen Moltmann: "a base de toda democracia é a igualdade de seus cidadãos." (MOLTMANN, 2012, p. 196). Afinal, segundo o pensamento de Edgar Morin, apesar das diferenças 
econômicas, religiosas, sociais, etc, todos pertencem com igualdade à cidadania planetária.

\subsection{Educação comprometida com o desenvolvimento humano e a cultura da solidariedade}

O artigo XXVI - 2 da Declaração Universal dos Direitos Humanos afirma categoricamente: "a instrução será orientada no sentido do pleno desenvolvimento da personalidade humana e do fortalecimento e do respeito pelos direitos humanos e pelas liberdades fundamentais". Nesse sentido, a Constituição Federal está em diálogo com a Declaração Universal de 1948, ao colocar o pleno desenvolvimento da pessoa como um dos objetivos fundamentais da educação, no artigo 205.

O pleno desenvolvimento humano está conectado com o princípio da dignidade humana. De um lado não é possível o ser humano desenvolver-se plenamente sem uma sólida educação; por outro lado, a educação que contribui para o pleno desenvolvimento humano é consequentemente uma educação que está promovendo a dignidade humana. Esta, é um dos fundamentos dos direitos humanos. Percebe-se de forma evidente a estreita relação entre os elementos nesse contexto.

O ser humano que foi educado a partir de uma educação em direitos humanos é também aquele que se desenvolveu de forma plena e é capaz de ajudar decisivamente para a construção de uma sociedade igual, justa e solidária, contribuindo dessa forma para a implementação da cultura da solidariedade. Construir uma sociedade solidária é um dos objetivos fundamentais da República Federativa do Brasil, nos termos do artigo $3^{\circ}$, inciso I da Constituição Federal. Portanto, todas as pessoas (jurídicas e físicas) devem necessariamente contribuir para a promoção da solidariedade.

O teólogo alemão Jürgen Moltmann, ao falar sobre a crise econômica de 2008, afirma que 
surgiu, por baixo da cultura de consumo que deplora as crises, uma cultura da solidariedade inteiramente diferente. A miséria dos desempregados e sem-tetos, dos empobrecidos e excluídos desencadeou uma inesperada onda de caridade nas grandes cidades do mundo ocidental. Surgiram bancos de alimentos, associações e grupos de vizinhos com os quais ninguém contava. Porque se salva a vida de inúmeras pessoas por meio dessas iniciativas, deveríamos superar a atual crise econômica não por meio da restauração da antiga cultura do consumo, mas da construção dessa cultura da solidariedade e propor diretrizes para uma sociedade pós-capitalista. (MOLTMANN, 2012, p. 190).

A promoção da cultura da solidariedade é questão fundamental para a sobrevivência humana em tempos onde o individualismo é mais importante do que a noção de comunidade. Aqui reside uma importante implicação para as religiões. $\mathrm{Na}$ essência religiosa existe sempre um convite para a prática solidária. Como exemplo, a narrativa cristã do primeiro século destaca: "A multidão dos fiéis era um só coração e uma só alma. Ninguém considerava propriedade sua o que possuía. Tudo entre eles era comum. Com grande eficácia os apóstolos davam testemunho da ressurreição do Senhor e todos os fiéis gozavam de grande estima. Não havia necessitados entre eles [...] repartia-se a cada um segundo sua necessidade" (Atos 4, 32-35). O senso de comunidade presente entre aqueles cristãos é um admirável exemplo num mundo onde impera a frieza social. Contudo, não apenas no cristianismo, é possível dizer que nas religiões em geral a solidariedade se faz presente. O professor Cláudio Ribeiro ao tratar do conceito de interculturalidade, lembra que o mesmo contribui para a convivência solidária e harmoniosa das religiões. Nas suas palavras,

no caso das religiões, a interculturalidade visa a fazer com que elas vivam em solidariedade e mutualidade, em abertura ao outro e em comunicabilidade harmoniosa e respeitosa entre os seres humanos, em desapego às tradições cristalizadas, a fim de construir um mundo a partir das pessoas, grupos e instituições de boa vontade e das experiências propositivas, plurais e de alteridade. (RIBEIRO, 2016, p. 51).

A solidariedade encontrou espaço privilegiado nas religiões e nas teologias da América Latina, especificamente a teologia da libertação. É possível dizer que no contexto teológico da teologia da libertação, que tem em Gustavo Gutierrez o seu principal referencial, a solidariedade é um paradigma que deve nortear a práxis cristã e orientar a conduta de todos os homens e mulheres. Essa é com toda certeza, 
uma concepção contra hegemônica de direitos humanos capaz de enfrentar os desafios que atingem profundamente a sociedade contemporânea. Nesse aspecto, como bem ensinou Boaventura de Souza Santos, "todas as religiões têm, em princípio, o mesmo potencial para desenvolver versões de teologias progressistas e libertadoras, capazes de se integrar nas lutas contra-hegemônicas contra a globalização neoliberal" (SANTOS, 2014, p. 147). Assim, é necessário que as religiões brasileiras se integrem nas lutas contra-hegemônicas e desenvolvam uma educação em direitos humanos capaz de promover o pleno desenvolvimento humano e construir uma a cultura da solidariedade.

O exemplo da narrativa acima é específico da tradição religiosa cristã. Contudo, outras religiões poderiam ser exemplificadas, pois a prática da caridade, da solidariedade e da partilha estão presentes nos textos e liturgias fundamentais. Compete às religiões explorarem essa perspectiva no sentido de promover uma educação comprometida com cultura da solidariedade justamente na direção contrária aos grupos que utilizam a religião para explorar economicamente os fiéis. É fundamental que a defesa aos direitos humanos esteja pautada no dia a dia das religiões. Assim, as religiões promovem uma educação em direitos humanos e contribuem para a construção de uma sociedade livre, igual e solidária.

\subsection{A educação em direitos humanos promove a amizade entre diferentes religiões}

O artigo 26 da Declaração Universal em Direitos Humanos afirma que "a instrução promoverá a compreensão, a tolerância e a amizade entre todas as nações e grupos raciais ou religiosos". Como depreende-se do texto de 1948, uma educação que fortalece e respeite os direitos humanos contribui para a tolerância e a amizade entre pessoas de diferentes nacionalidades e credos religiosos. E as religiões podem contribuir de maneira significativa. Com precisão, ensina o professor Afonso Maria Ligório Soares: "Budistas, cristãos e umbandistas podem se unir em defesa da vida, da ecologia e pela erradicação da pobreza." (SOARES, 2012, p. 233). Certamente, um dos principais desafios da atualidade é a prática de 
uma educação que ensine a tolerância e a amizade. Nesse contexto, as religiões desempenham papel fundamental, pois podem ultrapassar os limites de ensinamentos doutrinários para um discurso que compreenda valores fundamentais à sobrevivência humana.

Se na economia a teoria da dependência demonstrou que não é possível um país sobreviver de forma isolada, na educação certamente não é diferente. Em qualquer nível de formação, a sala de aula deverá ser sempre um espaço para construção de uma educação global, que considere os desafios impostos a nível mundial e não apenas local. Nesse mesmo caminho, a religião não pode se dar ao luxo de olhar apenas para si mesma, sem deixar de considerar os grandes desafios e problemas da humanidade ao seu redor. A xenofobia é um dos grandes problemas da atualidade. A sociedade avançada tecnologicamente, marcada pela mobilidade humana e civilizada, convive com um número crescente de intolerância religiosa, racismo e violência com os estrangeiros. Diante desse contexto, é urgente a interdisciplinaridade entre educação, direitos humanos e religião no sentido de promover um discurso que possibilite as pessoas compreender que a sobrevivência humana depende das relações saudáveis, da amizade, da tolerância.

A intolerância religiosa é uma praga a ser combatida. Lamentavelmente, em pleno século XXI, pessoas sentem-se no direito de agredir verbal e fisicamente o outro por motivos religiosos. As violências são dos mais variados tipos: palavras, pedras, avião, bombas, e diversos outros elementos são arremessados no outro pelo simples fato de não se concordar com a religião alheia. Consolidou-se aos poucos e de variadas formas a cultura da intolerância religiosa. Por essa razão, deve-se fortalecer a cultura da educação em direitos humanos, que eduque para a amizade, fortalecimento das relações pessoais e o respeito ao diferente. É necessário um trabalho conjunto para promover a cultura da amizade e do respeito.

É com o teólogo alemão Jürgen Moltamann que mais uma vez estabelecemos uma relação de diálogo entre a Declaração Universal de Direitos Humanos, possibilitando contribuição significativa para que as religiões promovam 
uma educação em direitos humanos, tendo como objetivo a amizade entre pessoas de diferentes religiões e nacionalidades. Para Moltmann,

amizade não é nenhum sentimento passageiro de afeto. Ela une afeto com fidelidade. No amigo ou na amiga a gente pode confiar. Como amigo ou como amiga nós nos tornamos confiáveis aos outros. Simplesmente estamos aí, como uma estrela está no céu. Amigos permanecem mesmo na desgraça. Entre amigos não existem preconceitos que prendam, como também modelos ideais que pretendam modificar. Por isso também a gente a constante necessidade de angustiadamente certificar-se da amizade. A verdadeira amizade não é uma ligação para utilidade comum como entre amigos de esporte ou amigos de negócio, mas uma ligação entre pessoas por causa delas mesmas. Entre pessoas amigas reina a confiança de que se há de acompanhar e ser acompanhado com amor e de se estar aí um para o outro, portanto uma fidelidade que não se dirige ao que se faz ou ao que se tem, mas sim à pessoa e ao seu caminho de vida. (MOLTMANN, 2010, p. 239).

Nas palavras do teólogo alemão, a hipótese de que a educação em direitos humanos contribui para a promoção da amizade e para a luta contra o preconceito é ainda mais concreta e real. Quando a educação em direitos humanos se consolidar no discurso e nas práticas religiosas, a amizade aberta e a tolerância religiosa serão realidades na sociedade. Essa amizade aberta, que não tem modelos ideais que pretendam modificar, é a amizade que possibilita o desenvolvimento do outro, o respeito, o carinho, o afeto, a confiança. O desenvolvimento tecnológico trouxe muitas facilidades para a vida humana, mas ao mesmo tempo promoveu distanciamentos e esfriamento nas relações interpessoais. Diante desse quadro, a amizade enfraqueceu de uma maneira assustadora, enquanto a inimizade cresceu (e cresce) assustadoramente. Portanto, é necessário que as religiões promovam a amizade entre si e busquem juntas contribuírem para elevar a dignidade humana a um patamar cada vez mais sólido. Nesse contexto, a alteridade sempre será fundamental. Na argumentação das professoras Flávia Piovesan e Melina Fachin,

os Direitos Humanos invocam o idioma da alteridade: ver no outro um ser merecedor de igual consideração e profundo respeito, dotado do direito de desenvolver as potencialidades humanas, de forma livre, autônoma e plena. Daí a urgência em potencializar e difundir a ideologia emancipatória da educação em Direitos Humanos. Ela tem um potencial transformador, empodera os sujeitos, mudando os seus mundos e dandolhes ferramentas para coletivamente, em ação política conjunta, mudar o mundo. Na ordem contemporânea caracterizada por crescentes 
hostilidades, intolerância e pelo fortalecimento do discurso do ódio, hoje, mais do que nunca, há que se expandir, potencializar e difundir a ideologia transformadora dos Direitos Humanos, como racionalidade de resistência e a única plataforma emancipatória de nosso tempo. (FACHIN; PIOVESAN, 2017, p. 36).

Diante de uma cultura hegemônica que não coloca freios no capitalismo e nem limites no lucro, somente a educação contra hegemônica dos direitos humanos poderá contribuir de maneira significativa e relevante para combater todos os tipos de violência, preconceitos e discriminação que existem na sociedade. A educação em direitos humanos é capaz de promover o resgate das relações sociais e interpessoais, que não visam vantagens e lucros, mas que fortalece os laços de amizade, respeito e tolerância. É nesse contexto que a educação e as religiões podem alinhar-se na promoção dos direitos humanos e contribuírem para a construção de uma sociedade onde a justiça, a igualdade, o desenvolvimento humano e a solidariedade, não sejam apenas utopias longe da realidade, mas sim fundamentos presentes nas relações humanos do cotidiano, capazes de transformar de fato e de direito a sociedade. O caminho é longo. Caminhar é necessário e urgente.

\section{Considerações finais}

A religião, a educação e os direitos humanos devem aprofundar cada vez mais suas relações, com a finalidade de contribuírem para o bem mais importante que existe: a vida. $\mathrm{O}$ presente texto apresentou de forma clara que o direito à educação de qualidade é uma garantia que deve contemplar todas as pessoas. A tecnologia tem um enorme potencial para garantir que esse direito alcance todas as

pessoas. Portanto, não existem justificativas para privar o brasileiro desse direito fundamental. Nesse mesmo sentido, o texto evidenciou que somente uma educação de qualidade pode cumprir com os objetivos propostos pelo artigo 205 da Carta constitucional, tais como o desenvolvimento da personalidade humana, o preparo para exercer a cidadania e a capacitação para o mercado de trabalho. 
A luta pelo direito à educação de qualidade deve ser irrestrita, constante e sem cessar. Pois somente ela pode formar cidadãos conscientes do valor e da importância dos direitos humanos. Nesse sentido, todas as instituições devem caminhar na mesma direção. No mundo globalizado, onde não existe atitude isolada, a sobrevivência humana depende do comportamento individual de cada um. Portanto, é necessário criar, promover e fortalecer a cultura da educação em direitos humanos. Esse é um dos principais desafios da atualidade. E aqui as religiões desempenham papel fundamental, pois tem força institucional significativamente capaz de contribuir e promover a educação em direitos humanos.

A sociedade brasileira é formada majoritariamente por pessoas que confessam alguma religião. Ao lado das pessoas que não confessam nenhum tipo de religião, todos juntos podem contribuir de maneira significativa para promover a igualdade, reduzindo todas as formas de preconceitos e diminuindo as desigualdades. Assim, é possível o pleno desenvolvimento da personalidade humana e uma prática cada vez mais constante da solidariedade e da tolerância. Esta é indispensável na convivência entre pessoas de diferentes religiões e nacionalidades. No Brasil existe espaço para os mulçumanos, cristãos, judeus, umbandistas, espíritas, budistas, candomblecistas, ateus, agnósticos, entre outras expressões, religiosas e não religiosas. Mas, não existe espaço para violência e para a intolerância. Esse é o caminho possível para criar e fortalecer a cultura da educação em direitos humanos. Trata-se de um desafio que diz respeito a todas as pessoas. Pela influência que as religiões desenvolvem na vida das pessoas e na cultura brasileira, sua contribuição pode ser significativa. Desenvolver, promover e fortalecer o diálogo entre religião, educação e direitos humanos, certamente terá como consequência a consolidação da cultura da solidariedade, da cidadania e dos direitos humanos na sociedade brasileira. 


\section{REFERÊNCIAS}

AGRA, Walber. Comentário ao artigo $1^{\circ}$ da CF (in) SARLET, Ingo Wolfgang; LENIO,

Streck; MENDES, Gilmar. Comentários à Constituição Federal. São Paulo: Saraiva, 2013 .

BRASIL. Constituição da República Federativa do Brasil. 1988.

BRASIL. Lei de Diretrizes e Bases da Educação. 1997.

CARNEIRO, Moacir. LDB fácil. Petrópolis: Editora Vozes, 2015.

CASTILHO, Ricardo. Educação em direitos humanos. São Paulo: Saraiva, 2016.

FACHIN, Melina; PIOVENSA, Flávia. Educação em direitos humanos no brasil: desafios e perspectivas. Revista Jurídica da Presidência, Brasília, v. 19, n. 117, p. 20-38, fev./maio 2017.

FIGUEIRA, Eulálio; JUNQUEIRA, Sérgio. Teologia e educação. São Paulo: Paulinas, 2012.

HARARI, Yuval Noah. Lições para o século XXI. São Paulo: Companhia das Letras, 2018.

MALISKA, Marcos Augusto; Comentário ao artigo 205. In: SARLET, Ingo Wolfgang;

LENIO, Streck; MENDES, Gilmar. Comentários à Constituição Federal. São Paulo:

Saraiva, 2013.

MAZZUOLI, Valério de Oliveira. Curso de direitos humanos. São Paulo: Método, 2017.

MENDES, Gilmar. Curso de direito constitucional. São Paulo: Saraiva, 2018.

MOLTMANN, Jürgen. Ética da esperança. Petrópolis: Vozes, 2012.

MOLTMANN, Jürgen. O espírito da vida. Petrópolis: Vozes, 2010.

ONU - Organização das Nações Unidas. 1948.

PIAGET, Jean. Educação para quem? São Paulo: Editora José Olímpio, 1990.

RIBEIRO, Cláudio de Oliveira. Religião, democracia e direitos humanos. São Paulo: Editora Reflexão, 2016.

ROSSI, Luiz Alexandre; JUNQUEIRA, Sérgio. Religião, laicidade e direitos humanos. São Paulo: Fonte Editorial, 2015.

SANTOS, Boaventura de Souza. Se Deus fosse um ativista dos direitos humanos.

São Paulo: Cortez, 2014. 
SARLET, Ingo Wolfgang; LENIO, Streck; MENDES, Gilmar. Comentários à

Constituição Federal. São Paulo: Saraiva, 2013.

SILVA, José Afonso da. Direito constitucional positivo. São Paulo: Malheiros, 2018.

SOARES, Afonso Maria Ligório. Educação e pluralidade religiosa. In: FIGUEIRA, Eulálio; JUNQUEIRA, Sérgio. Teologia e educação. São Paulo: Paulinas, 2012.

TAVARES, André Ramos. Curso de direito constitucional. São Paulo: Saraiva, 2018. 